\title{
Knowledge about anesthesiology and the anesthesiologists among patients in a tertiary care hospital in Saudi Arabia
}

\author{
Shankar Lal' ${ }^{1}$, Rifai Derar ${ }^{2}$, Muhammad Anwar Malik ${ }^{3}$ \\ 1 - Our Lady of Lourdes, RCSI Group of Hospitals, Ireland; E-mail: shankar.anaesthesia1@gmail.com \\ 2 - National Guards Health Affairs, Department of Anesthesia, Riyadh, KSA; R-mail: derar1971@yahoo.com \\ 3 - Our Lady of Lourdes, RCSI Group of Hospitals, Ireland; E-mail: manwarmalik@yahoo.com
}

Correspondence: Dr. Muhammad Anwar Malik; E-mail: manwarmalik@yahoo.com; Mobile: 353868571406

\section{Abstract}

Object: With the rapid proliferation of the electronic media, the general public is considered to be well-aware of the working of the different branches of medicine as well as the specialists practicing in these disciplines. We aimed to determine the knowledge of patients reporting to our hospital about an anesthesiologist's role and responsibilities along with the field of the anesthesiology.

Methodology: This cross-sectional survey was carried out at National Guard Health Affairs, from 1st December 2017 to 30th March 2018. After informed consent, patients were asked to answer the questionnaire comprising of 12 open-ended questions regarding their knowledge about anesthesiologist and anesthesiology. Scoring as per correct and incorrect questions was done using SPSS Inc., Chicago, IL version 19.

Results: The four months cross-sectional survey included 385 patients from our teaching hospital. Variables recorded included age, gender, type of surgery, educational level, occupation, and previous surgery. The majority of the patients 375 (97.4\%) had very poor knowledge about anesthesiology and the role of the anesthesiologists, while only $10(2.6 \%)$ patients were found knowledgeable about anesthesiologists $(p<0.05)$.

Conclusion: Knowledge about the role of the anesthesiologist and the anesthesiology in the healthcare system is very poor among Saudi patients. There is a strong need to spread awareness about anesthesiology and the anesthesiologist among common people to increase communication for the betterment of society.

Key words: Anesthesia; Anesthesiologists; Knowledge; Questionnaire.

Citation: Lal S, Derar R, Malik M. Knowledge about anesthesiology and the anesthesiologists among patients in a tertiary care hospital in Saudi Arabia. Anaesth. pain intensive care 2020;24(5):497-502

Received: 27 May 2020, Reviewed: 15 June 2020, Accepted: 30 June 2020

\section{Introduction}

Anesthesiology is still an emerging specialty in comparison to many other branches of medicine and surgery. ${ }^{1}$ Infrequent exposure, and limited direct patient interaction with the anesthesiologists have resulted in very little knowledge regarding the field of anesthesiology among patients getting admission to hospitals. ${ }^{2,3}$ The role and the status of the anesthesiologist, and the awareness about the specialty of anesthesiology has always been an discussion topic in the general population of most of the countries. Ongoing advancement in the field of anesthesiology has facilitated complex surgical procedures, but it has never been acknowledged in media. ${ }^{3}$ Several studies done on the same subject is a reflection of the efforts of professional bodies around the world towards improvement in the spread of awareness about the field of anesthesiology and role of the anesthesiologist, but these are still largely inadequate..$^{4,5,6}$

A survey done even in developed countries outside the operating rooms depicted that the patients have very limited awareness about the role of anesthesiologists. A survey done in India in 2018 showed that there was widespread ignorance about 
anesthesiology and the role of the anesthesiologist in patients attending rural healthcare facilities. ${ }^{1}$ A 2009 survey in a busy government setting of India showed that only $56 \%$ of patients knew that an anesthesiologist is a doctor. ${ }^{6,7}$ A survey done in the year 2004 revealed a high number of around $80 \%$ of patients visiting the hospital recognized an anesthesiologist as a doctor, but were unaware of their responsibilities in the hospital. ${ }^{8,9}$

In the era of the rise in media and the Internet, an enhancement can be seen in awareness about anesthesiology. Awareness about anesthesiology and anesthesiologists is important in order to maintain a better relationship between patients and the doctor. ${ }^{9}$ We conducted this questionnaire based study among Saudi patients coming to our hospital regarding anesthesiology and the role of the anesthesiologists.

\section{Methodology}

A cross-sectional study was conducted at the National Guard Health Affairs, Riyadh, Saudi Arabia from 1st December 2017 to 30th March 2018. The sample size was calculated using the WHO Sample Size Calculator. In a previous study, ${ }^{6}$ knowledge regarding anesthesiologists and anesthesiology was about $51.52 \%$, therefore 384 patients were included in this study to estimate knowledge within 5 per cent point (margin of error) of the true value $(51.52 \%)$ with $95 \%$ confidence interval. Using non-probability purposive sampling patients falling in inclusion criteria were included after taking ethical committee approval and patient's consent.

Patients of either sex, aged 18 to 60 years were included regardless of the specialty of surgery. We excluded those patients who refused to give consent and those were unable to give consent due to language bearer, mentally not able to understand questionnaires and doctors who were admitted as patients.

Knowledge about anesthesiologists and the field of anesthesiology was measured by asking the questionnaire comprising 12 questions. Patients were interviewed by the pre-operative anesthetist and principal investigator on ward. Each interview lasted for 10-20 $\mathrm{min}$ and was based on a questionnaire in English and Arabic languages. Questionnaire consisted of questions modified from previous studies and added questions. ${ }^{2-9}$ It had two parts; demographics i.e. age, gender, educational level, occupation, previous anesthesia experience and the type of surgery, the second part consisted of 12 questions about anesthesiology and anesthesiologist. Patients giving the correct response to 8 out of 12 questions were considered to be knowledgeable.

Data were analyzed using Statistical Packages for Social Science version 19 (SPSS Inc., Chicago, IL). Frequency and percentages were computed for gender, type of surgery, education level, previous surgery, and patient's knowledge about anesthesiology and anesthesiologist. Mean and standard deviation was estimated for age. Stratification was done to control effect modifiers like gender, age, education level, previous surgery to observe the patient's knowledge about anesthesiology and anesthesiologist through the chisquare test. $\mathrm{P} \leq 0.05$ was considered as significant.

\section{Results}

The demographics of the study population, included age, gender, education level, profession shown in Table 1.

None of the patients refused enrolment, responses on 12 different questions were recorded, patients giving 8 correct answers out of 12 were labelled as having adequate knowledge of anesthesiology and

Table 1: Demographic characteristics ( $n=385)$

\begin{tabular}{|l|c|}
\hline \multicolumn{1}{|c|}{ Variables } & Frequency (\%) \\
\hline Age Groups (Years) & \\
$\leq 50$ & $84(21.8)$ \\
$31-40$ & $98(25.5)$ \\
$41-50$ & $86(22.3)$ \\
$51-60$ & $54(14)$ \\
$>60$ & $63(16.4)$ \\
\hline Gender & $198(51.4)$ \\
Male & $187(48.6)$ \\
Female & \\
\hline Education & $164(42.6)$ \\
Secondary & $207(53.8)$ \\
Matric or Intermediate & $14(3.7)$ \\
Graduate or post & \\
Graduate & \\
\hline Profession man/ & $204(53)$ \\
Business & \\
Employee & $172(44.7)$ \\
House wife & $9(2.3)$ \\
Nurse & \\
\hline
\end{tabular}


Table 2.1: Knowledge of patients regarding the specialty of anesthesiology and the anesthesiologists $(n=385)$

\begin{tabular}{|c|c|c|}
\hline Questions & Response & $\mathbf{N}(\%)$ \\
\hline 1. Have you heard about anesthesia before? & $\begin{array}{l}\text { Yes } \\
\text { No }\end{array}$ & $\begin{array}{l}103(26.8) \\
282(73.2)\end{array}$ \\
\hline 2. Has your surgeon told you anything about anesthesia? & $\begin{array}{l}\text { Yes } \\
\text { No }\end{array}$ & $\begin{array}{l}321(83.4) \\
64(16.6)\end{array}$ \\
\hline 3. Do you know there are different types of anesthesia? & $\begin{array}{l}\text { Yes } \\
\text { No }\end{array}$ & $\begin{array}{l}122(31.7) \\
263(68.3)\end{array}$ \\
\hline 4. If yes what is the most common type of anesthesia $(n=122)$ ? & $\begin{array}{l}\text { General } \\
\text { Spinal / epidural } \\
\text { Local }\end{array}$ & $\begin{array}{l}83(68) \\
31(25.4) \\
8(6.6)\end{array}$ \\
\hline 5. Is anesthesiology a separate specialty? & $\begin{array}{l}\text { Yes } \\
\text { No }\end{array}$ & $\begin{array}{l}106(27.5) \\
279(72.5)\end{array}$ \\
\hline 6. How is patient kept asleep during surgery? & $\begin{array}{l}\text { I.V injections } \\
\text { Gases }\end{array}$ & $\begin{array}{l}344(89.4) \\
41(10.6)\end{array}$ \\
\hline 7. Anesthesia is provided by: & $\begin{array}{l}\text { Doctor } \\
\text { Nurse } \\
\text { Technician }\end{array}$ & $\begin{array}{l}31(8.1) \\
352(91.4) \\
2(0.5)\end{array}$ \\
\hline 8. How many years of training does & $\begin{array}{l}1-2 \\
3-4\end{array}$ & $\begin{array}{l}378(98.2) \\
7(1.9)\end{array}$ \\
\hline
\end{tabular}

Table 2.2: Patients Knowledge about specialty of anesthesiology and the anesthesiologists

\begin{tabular}{|c|c|}
\hline Questions & Response (\%) \\
\hline $\begin{array}{l}\text { Perioperative well-being of patient is } \\
\text { responsibility of: } \\
\text { a. Surgeon } \\
\text { b. Anesthesiologist } \\
\text { c. Both }\end{array}$ & $\begin{array}{c}: \\
372(96.6) \\
12(3.1) \\
1(0.3)\end{array}$ \\
\hline $\begin{array}{l}\text { What does anesthesiologist do in } \\
\text { operating room? } \\
\text { a. Give Drugs } \\
\text { b. Monitor the patient } \\
\text { c. Helps the surgeon } \\
\text { d. Don't know }\end{array}$ & $\begin{array}{c}354(91.9) \\
11(2.9) \\
6(1.6) \\
14(3.6)\end{array}$ \\
\hline $\begin{array}{l}\text { Who ensures your well-being (BP, } \\
\text { heart rate, ECG, respiration) in the } \\
\text { operating room? } \\
\text { a. Nurse } \\
\text { b. Anesthesiologist } \\
\text { c. Surgeon } \\
\text { d. Technician }\end{array}$ & $\begin{aligned} 354 & (91.9) \\
10 & (2.6) \\
11 & (2.9) \\
10 & (2.6)\end{aligned}$ \\
\hline $\begin{array}{l}\text { Who looks after the patient in } \\
\text { recovery room } \\
\text { a. Nurse alone } \\
\text { b. Nurse supervised by Anesth } \\
\text { c. Nurse supervised by Surgeon }\end{array}$ & $\begin{array}{c}288(74.8) \\
4(1) \\
93(24.2)\end{array}$ \\
\hline $\begin{array}{l}\text { In what areas in the hospital does the } \\
\text { anesthesiologist take care of } \\
\text { patients? } \\
\text { a. Operating room (only) } \\
\text { b. Intensive care unit (ICU) } \\
\text { c. In pain management services } \\
\text { and pain clinic }\end{array}$ & $\begin{array}{c}353(91.7) \\
22(5.7) \\
10(2.6)\end{array}$ \\
\hline
\end{tabular}

Table 3: Patients perception

\begin{tabular}{|c|c|}
\hline Patients perception & $\mathbf{N}(\%)$ \\
\hline $\begin{array}{l}\text { Visit to preoperative anesthesia } \\
\text { clinic is important? } \\
\text { a. Yes } \\
\text { b. No }\end{array}$ & $\begin{array}{c}30(7.8) \\
355 \\
(92.2)\end{array}$ \\
\hline $\begin{array}{l}\text { Do you want further information } \\
\text { about anesthesia? } \\
\text { a. Yes } \\
\text { b. No }\end{array}$ & $\begin{array}{c}159 \\
(41.3) \\
226 \\
(58.7)\end{array}$ \\
\hline Are you afraid of anesthesia & $385(100)$ \\
\hline $\begin{array}{l}\text { Who do you think is more important? } \\
\text { a. Surgeon } \\
\text { b. Anesthesiologist } \\
\text { Both are equal }\end{array}$ & $\begin{array}{l}373 \\
(96.9) \\
7(1.8) \\
5(1.3)\end{array}$ \\
\hline
\end{tabular}

Anesthesiologist. Out of 385 patients, only 10 patients responded adequately $(2.60 \%)$, while 375 $(97.40 \%)$ were labelled poor in the knowledge of anesthesiology and anesthetists as shown in Table 2.

When these responses were compared between previous studies, statistically significant results came out. During survey we also tested patients perception based on their opinion about visit to anesthesia clinic, desire to know further about anesthesia, their fear to get anesthesia and were also evaluated on their perception about who is more important between surgeon, Anesthesiologist or 
both we got results that show people are less interested in knowing about anesthesia and still consider surgeon fully responsible for everything, shown in (Table 3 ).

\section{Figure 1: Knowledge of patients regarding anesthesiology and the anesthesiologists $(n=385)$}

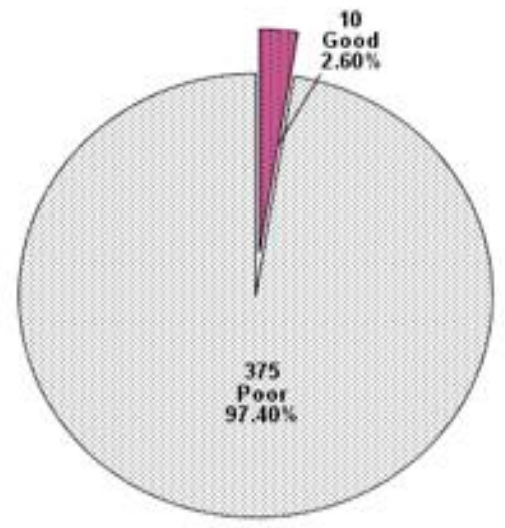

\section{Discussion}

This is probably the first national survey best to our knowledge in the Kingdom of Saudi Arabia exploring patients' awareness attending to National Guard Health Affairs Riyadh about the specialty of anesthesiology and the anesthetist. There are multiple surveys of such nature that have been performed throughout the world, mostly done on patients in single small setups or a few hospitals, ${ }^{10-}$ 19 exploring patients' awareness of different educational levels in a small setup. We did the survey in the largest trauma center of Asia, and our results accurately explain the awareness about anesthesiology and Anesthesiologist in a hugely populated region.

In the present study, $73.2 \%$ of respondents heard about anesthesia for the first time, and only $31.7 \%$ knew about different types of anesthesia. Moreover, detailed results have shown that even respondents who knew had very little knowledge of the actual roles and responsibilities of an Anesthesiologist, and this level of knowledge in comparison to other surveys is extremely low. ${ }^{10-19} 72.5 \%$ did not believe anesthesia as a separate specialty. A huge number of $89.4 \%$ of patients knew anesthesia is given only by IV injections, $10.8 \%$ believed gases can be usefor induction of anesthesia. A further survey revealed that $91.4 \%$ patients believed that anesthesia, if given by nurse, is not a job of a doctor while $8.1 \%$ of patients believed vice versa. While asking about training in anesthesia $98.2 \%$ responded it to be $1-2$ years. During surgery, $2.9 \%$ of them answered that the surgeon is in charge of monitoring vital signs, even though this is one of the most important roles of anesthesiologists. Strikingly, even the nurse was more likely to be selected as responsible for this role (91.9\%), and only $2.6 \%$ of people chose the anesthesiologist similar in number to those who selected surgeon, considerably lower than in other surveys. ${ }^{10-19}$ Also, the majority of participants $(74.8 \%)$ believed that the recovery is done by a nurse and $24.2 \%$ said the nurse is supervised by the surgeon in comparison to only $1 \%$ who believed the anesthetist to be behind the care of the patient in recovery. Although many $(91.7 \%)$ of those surveyed believed that the anesthesiologist gave care only to patients in theatre for surgery, most of them seemed to have very little understanding of the province of care in intensive care unit $(5.7 \%)$ and pain management services/pain clinic $(2.6 \%)$ indicating that the public has little understanding of the actual roles of an anesthesiologist.

In our current survey, we explored that, interestingly, the patients who had a prior history of surgeries under anesthesia were more likely to believe the surgeon as responsible for some responsibility for some intraoperative management and that nurses are in charge of recovery supervised by anesthetists. Such results probably may be because the surgeons explain to patients about surgery before the operation and visit them postoperatively, leading them to believe that the surgeon plays a key role in most areas of surgery, including anesthesia. Moreover, most of the patients directly ask for nurses if suffering any issues in immediate recovery. Most anesthesiologists visit the patients only one time before surgery either in the clinic or the ward and this is totally in contrast to surgeons, although some survey has found that patient orientation in the pre-anesthetic/pre-surgery visit is a way of developing repo and achieving patient recognition. ${ }^{11,17,20}$ In this survey, $58.7 \%$ of participants indicated a desire for information about anesthesia from an anesthesiologist and it indicates that there is a huge Gap in the Doctor-Patient relationship in Anesthesia. Dedicated personal care including postoperative visits is one of the most important factors affecting the perception of the anesthesiologist. Our survey revealed that $96.9 \%$ of patients think the Surgeon is more important than anesthesiologists, whom only $1.8 \%$ of patients 
believed to be of value, while $1.3 \%$ considered both equally important. One study reported that the perception of the anesthesiologist and satisfaction were significantly increased by a single postoperative visit by the anesthesiologist. ${ }^{21}$

Our results showed all patients (100\%) after explaining anesthesia were found to be afraid of it. None of those surveyed experienced the roles of anesthesiologists via the television, and the results were similarly ordered in both groups (Information Brochure > friends/relatives > internet/television). In the past few years, the Kingdom of Saudi Arabia produced a simple but informative cartoon brochure that was distributed to hospitals nationwide. We consider that the most frequent source of media awareness about anesthesiologists is social media, television programs because the public seems to prefer to be informed by methods already present in their daily lives. For the provision of information most effectively, the National Society of Anesthesiology Kingdom of Saudi Arabia should consider the publics' thoughts and preferences, and periodic surveys every 5-10 years may be helpful to gather feedback from the public on their awareness about anesthesiology and anesthesiologist.

\section{Conclusion}

General population in Saudi Arabia does not have adequate knowledge about the specialty of anesthesiology and the responsibilities anesthesiologists hold inside and outside the operating room. We suggest that to enhance this awareness, in healthcare setups, every anesthesiologist should provide patients with more detailed information and explain the anesthetics role by a postoperative visit as well as a pre-operative visit to make it more comprehensive. Simultaneously, the national societies of anesthesiologists should provide systematic comprehensive information reflecting the common people's thoughts and preferences.

\section{Conflict of interest}

None declared by the authors

\section{Authors' contribution}

All authors took equal part in the concept, devising of the performa and conduct of survey and manuscript writing.

\section{References}

1. Klafta JM, Roizen MF. Current understanding of patients' attitudes toward and preparation for anesthesia: a review. Anesth Analg. 1996 Dec;83(6):1314-1321. [PubMed] DOI: 10.1097/00000539-199612000-00031

2. Calman LM, Mihalache A, Evron S, Ezri T. Current understanding of the patient's attitude toward the anesthetist's role and practice in Israel: effect of the patient's experience. J Clin Anesth. 2003 Sep;15(6):451-454. [PubMed] DOI: 10.1016/s09528180(03)00111-9

3. Hariharan S, Merritt-Charles L, Chen D. Patient perception of the role of anesthesiologists: a perspective from the Caribbean. J Clin Anesth. 2006 Nov;18(7):504-509. [PubMed] DOI: 10.1016/j.jclinane.2006.03.004

4. Khan F HS, Zaidi A. Patients view of the anaesthetist in a developing country. J Pak Med Assoc. 1999:49(1):4-7. [PubMed]

5. Braun AR, Leslie K, Morgan C, Bugler S. Patients' knowledge of the qualifications and roles of anaesthetists. Anaesth Intensive Care. 2007 Aug;35(4):570-574. [PubMed] DOI: 10.1177/0310057X0703500417

6. Mathur SK, Dube SK, Jain S. Knowledge about Anaesthesia and Anaesthesiologist Amongst General Population in India. Indian J Anaesth. 2009 Apr;53(2):179-186. [PubMed]

7. Tohmo H, Pälve H, Illman H. The work, duties and prestige of Finnish anesthesiologists: patients' view. Acta Anaesthesiol Scand. 2003 Jul;47(6):664-666. [PubMed] DOI: 10.1034/j.1399-6576.2003.00152.x

8. Ahsan UI Haq WA, Mubeen M. A survey of patients awareness about the peri-operative role of Anesthetists. Biomedica. 2004;20(1):5-9. [Free Full Text]

9. Shevde K, Panagopoulos G. A survey of 800 patients' knowledge, attitudes, and concerns regarding anesthesia. Anesth Analg. 1991 Aug;73(2):190-198. [PubMed] DOl: $\underline{\text { 10.1213/00000539-199108000-00013 }}$

10. Braun AR, Leslie K, Morgan C, Bugler S. Patients' knowledge of the qualifications and roles of anaesthetists. Anaesth Intensive Care. 2007 Aug:35(4):570-574. [PubMed] DOI: 10.1177/0310057X0703500417

11. Hariharan S, Merritt-Charles L, Chen D. Patient perception of the role of anesthesiologists: a perspective from the Caribbean. J Clin Anesth 2006;18:504-509. [PubMed] DOI: 10.1016/i.jclinane.2006.03.004

12. Baaj J, Takrouri MS, Hussein BM, Al Ayyaf H. Saudi patients' knowledge and attitude toward anesthesia and anesthesiologists--A prospective cross-sectional interview questionnaire. Middle East J Anaesthesiol. 2006 Feb;18(4):679-691. [PubMed]

13. Irwin MG. Fung SK, Tivey S. Patients' knowledge of and attitudes towards anaesthesia and anaesthetists in Hong Kong. Hong Kong Med J. 1998 Mar;4(1):1622. [PubMed] 
14. Swinhoe CF, Groves ER. Patients' knowledge of anaesthetic practice and the rôle of anaesthetists. Anaesthesia. 1994 Feb;49(2):165-166. [PubMed] DOI: 10.1111/j.1365-2044.1994.tb03380.x

15. Tohmo H, Pälve $\mathrm{H}$, Illman $\mathrm{H}$. The work, duties and prestige of Finnish anesthesiologists: patients' view. Acta Anaesthesiol Scand. 2003 Jul;47(6):664-666. [PubMed] DOI: 10.1034/j.1399-6576.2003.00152.x

16. de Oliveira KF, Clivatti J, Munechika M, Falcão LF. What do patients know about the work of anesthesiologists? Rev Bras Anestesiol. 2011 NovDec;61(6):720-727. [PubMed] DOI: 10.1016/S00347094(11)70081-2

17. Calman LM, Mihalache A, Evron S, Ezri T. Current understanding of the patient's attitude toward the anesthetist's role and practice in Israel: effect of the patient's experience. J Clin Anesth. 2003 Sep;15(6):451-454. [PubMed] DOI: 10.1016/s0952$\underline{8180(03) 00111-9}$
18. Huang $\mathrm{Y}$, Yang K, Ren H, Luo A. A survey of elective surgical patients' attitudes toward anesthesia in PUMC hospital. Chin Med Sci J. 2002 Jun;17(2):7780. [PubMed]

19. Chew ST, Tan T, Tan SS, Ip-Yam PC. A survey of patients' knowledge of anaesthesia and perioperative care. Singapore Med J. 1998 Sep;39(9):399-402. [PubMed]

20. van Wijk MG, Smalhout B. A postoperative analysis of the patient's view of anaesthesia in a Netherlands' teaching hospital. Anaesthesia. 1990 Aug;45(8):679682. [PubMed] DOI: 10.1111//.13652044.1990.tb14399.x

21. Saal D, Heidegger T, Nuebling M, Germann R. Does a postoperative visit increase patient satisfaction with anaesthesia care? $\mathrm{Br} J$ Anaesth. 2011 Nov;107(5):703-709 [PubMed]

DOI: 